\title{
PARA (RE)LER "VOZES-MULHERES": CONCEIÇÃO EVARISTO E A DIALÉTICA DA ANCESTRALIDADE
}

\author{
To (re-)read "vozes-mulheres": Conceição Evaristo and the dialectics of \\ ancestrality
}

\author{
Henrique Marques Samyn \\ https://orcid.org/0000-0002-2624-3487 \\ Universidade do Estado do Rio de Janeiro, Centro de Educação e Humanidades, Rio de \\ Janeiro, RJ, Brasil. 20550-900 - ceh@uerj.br
}

\begin{abstract}
Resumo: O presente artigo tem por objetivo apresentar uma leitura para "Vozes-mulheres", um dos mais conhecidos poemas de Conceição Evaristo, publicado originalmente no livro Poemas da recordação e outros movimentos. Por intermédio de uma leitura em profundidade, que leve em consideração também o conjunto de elementos retóricos, formais e rítmicos presentes na composição, aqui se tenciona abordar o modo como o referido poema apresenta um complexo processo dialético, protagonizado exclusivamente por figuras femininas - a saber: a bisavó, a avó, a mãe, o próprio eu lírico e sua filha -, ao longo do qual estas alcançam a determinação de sua própria liberdade. Por conseguinte, neste artigo o que se pretende é não apenas apresentar uma inovadora leitura para "Vozes-mulheres", mas também contribuir de modo significativo para a fortuna crítica acerca da significativa produção poética de Conceição Evaristo - que, a despeito de sua importância, vem atraindo menos atenção de pesquisadores do que sua obra em prosa.
\end{abstract}

Palavras-chave: Poesia negro-brasileira. Conceição Evaristo. Poesia negra de autoria feminina. Dialética. Ancestralidade.

\begin{abstract}
This paper intends to develop an interpretation for "Vozes-mulheres", one of the most well-known poems by Conceição Evaristo, originally published in the book Poemas da recordação e outros movimentos. Through an in-depth reading that considers also rhetorical, formal and rhythmic elements of the composition, the paper intends to address how the poem presents a complex dialectic process, carried out exclusively by female figures - namely: the great-grandmother, the grandmother, the mother, the poetic speaker herself and the daughter , along which they reach the determination of their own freedom. Therefore, the paper aims to present not only an innovative reading to "Vozes-mulheres", but also to contribute in a relevant way to the critical studies on the poetical works by Conceição Evaristo, that have attracted less attention from researchers than her prose works.
\end{abstract}

Keywords: Afro-Brazilian poetry. Conceição Evaristo. Poetry by Black women. Dialetics. Ancestrality.

Esta obra está licenciada sob uma Creative Commons - Atribuição 4.0 
Publicado em Poemas da recordação e outros movimentos, livro originalmente publicado por Conceição Evaristo em 2008, "Vozes-mulheres" remete, já em seu título, a uma oralidade generificada, porque qualificada como feminina. Não sendo necessário ressaltar a importância da oralidade para a literatura africana e afrodiaspórica (IRELE, 2001; FINNEGAN, 2012), parece-me relevante considerar seu significado imediato: o que, numa primeira leitura, pode sugerir este título? A alusão à voz, no título de uma composição poética, remete ao que pode ser percebido como uma instância originária da própria poesia; não obstante, isso é matizado tanto pelo recurso ao plural quando pela marca do gênero - tratando-se, por conseguinte, de um discurso poético que diz respeito a um processo coletivo e feminino. Torna-se possível, desse modo, formular algumas questões que podem servir como ponto de partida: que tipo de processo é esse? Qual é o seu sentido? Que mulheres dele participam?

Considerando essas questões meramente como um caminho que possibilite uma abertura interpretativa, avancemos para o poema:

A voz de minha bisavó

ecoou criança nos porões do navio.

Ecoou lamentos

de uma infância perdida.

A voz de minha avó ecoou obediência aos brancos-donos de tudo.

A voz de minha mãe ecoou baixinho revolta no fundo das cozinhas alheias debaixo das trouxas roupagens sujas dos brancos pelo caminho empoeirado rumo à favela.

A minha voz ainda ecoa versos perplexos com rimas de sangue

$\mathrm{e}$

fome.

A voz de minha filha recolhe todas as nossas vozes recolhe em si as vozes mudas caladas engasgadas nas gargantas.

A voz de minha filha recolhe em si a fala e $o$ ato. O ontem - o hoje - o agora.

$\mathrm{Na}$ voz de minha filha 
se fará ouvir a ressonância

$\mathrm{O}$ eco da vida-liberdade.

(EVARISTO, 2017, p. 24-25).

Se a obra de Conceição Evaristo atualmente constitui um dos principais objetos de investigação no âmbito acadêmico, sendo objeto de incontáveis estudos desde a pioneira pesquisa de Maria Aparecida Andrade Salgueiro (2004) até a mais recente obra de Miriam Cristina dos Santos (2018), importa perceber que a maior parte desses estudos se dedica à sua produção em prosa. Sendo um dos mais conhecidos e citados poemas da referida autora, "Vozes-mulheres" vem sendo objeto de análises que nele divisam, sobretudo, elementos como a incorporação de elementos (auto)biográficos e o resgate de uma memória coletiva (NASCIMENTO, 2008; MENDES, 2009; SOARES; SANTOS; TEIXEIRA, 2018). Não desconsiderando a pertinência destas interpretações, meu objetivo aqui é propor uma leitura em profundidade que desvele a forma como Conceição Evaristo constrói seu poema de modo a não meramente evocar vozes abstratas, mas a fazer do próprio texto lírico um espaço de incorporação e de (re)produção dessas vozes - o que, a meu ver, demanda uma leitura atenta a elementos dialéticos que lhe são subjacentes. Para desenvolver apropriadamente a interpretação proposta, dividirei "Vozes-mulheres" em três segmentos de extensões desiguais: o primeiro, composto pelas três estâncias iniciais da composição; o segundo, constituído apenas pela quarta estrofe; e o terceiro, que compreende as duas estâncias derradeiras.

$\mathrm{O}$ primeiro segmento do poema encerra as referências mais explícitas às heranças da ancestralidade, que se concretizam em três figuras femininas: a bisavó, a avó e a mãe. Não obstante, cada uma dessas figuras se inscreve no âmbito de dinâmicas particulares, algo que se torna visível em uma leitura mais atenta. Importa perceber dois elementos que emergem de modo articulado: já de início, a dissonância que emerge entre a evocação da figura da bisavó que, inevitavelmente, remete à velhice - e à sua infância; e a inscrição dessa dissonância em um espaço específico: os "porões do navio". Esse par de elementos institui um duplo desajuste, uma vez que a imagem da bisavó não é resgatada em função dos atributos que lhe são próprios - por exemplo, a experiência, a maturidade ou a sabedoria -, mas a partir de um vazio que é imediatamente constatado entre a senescência e a infância, como se um vácuo houvesse entre um estágio e outro; isso pode suscitar a indagação: o que se fez, afinal, desta vida?

A resposta, conquanto já conhecida por quem lê o poema tendo em mente a história do povo negro, é matizada pelo segundo elemento aludido: a referência aos "porões do navio". Desse modo, é o deslocamento da existência - ainda na infância - para o espaço de sua anulação ontológica - o navio negreiro - o que enseja o referido esvaziamento (a transformação em objeto, mercadoria, moeda, conforme Mbembe, 2014): uma vez concretizado, esse movimento obsta a própria possibilidade de uma concretização existencial autônoma, destinando-a a, na melhor das hipóteses, um movimento reativo contra a opressão imposta. Isso quer dizer que a menção a uma "infância perdida" possui um sentido metonímico, visto que essa perda se refere, ao menos potencialmente, a toda a trajetória existencial: o que esperar de uma vida deslocada, desde seu princípio, para os porões de um "tumbeiro" - cujo nome, por óbvio, já remete à 
aniquilação? Não é por acidente que, no que diz respeito à bisavó, o poema remete apenas à infância e à velhice; penso que isso ocorre porque todo o intervalo entre uma e outra, submetido à opressão escravista, é nadificado.

Em termos formais, cabe perceber o elaborado arranjo métrico que favorece uma associação entre o segundo e o quarto versos, ambos pentassilábicos, reforçada pelo recurso à anáfora; desse modo, aproximam-se a infância e a lamentação. De modo mais sutil, pode-se ainda observar a articulação promovida, de um lado, pelas bilabiais oclusivas presentes em "bisavó", "porões" e "perdida"; e, de outro lado, as fricativas labiodentais presentes em "voz", "bisavóo", "navio" e "infầncia" - o que propicia uma conjugação entre o destino imposto à figura feminina e suas consequências.

Ressalte-se, entretanto, que já aqui é visível um primeiro movimento dialético, uma vez que a impossibilidade existencial da bisavó opera como condição de possibilidade para a existência que, no presente, se expressa liricamente na composição. A esse propósito, sobressai a transformação da "voz" originária, primeiro, em eco (portanto, em repetição); e, logo, em "lamentos" - que, por sua vez, aludem à posterior percepção (eventualmente, já na senescência) da perda da infância - cujo sentido, como anteriormente referido, pode ser visto como metonímico. Perceba-se, entretanto, que esses "lamentos" são agora resgatados por uma outra "voz": a própria voz lírica que constitui o texto poético.

A segunda figura evocada é a da avó, na estância mais breve da composição - o que, a meu ver, não ocorre por acaso. Fruto de ventre escravizado, à avó não resta alternativa, que não repetir a trajetória já trilhada por sua mãe; por conseguinte, a estrutura reduzida da estrofe manifesta textualmente a realidade de uma existência restringida aos limites impostos pela opressão escravista. O verso medial, nesse aspecto, é particularmente significativo, tanto por reduzir (novamente) a voz a seu eco quanto por associá-la a um ato de obediência: o que tudo isso enfatiza é a privação de autonomia de uma cativa em um mundo no qual nada lhe dizia respeito. É relevante perceber ainda que, neste momento, a questão racial é ostensivamente determinada: a nomeação dos "brancos-donos de tudo" identifica os responsáveis pelo estado de poder no âmbito do qual tanto à bisavó quanto à avó foi imposta a condição escravizada. Perceba-se como o uso das sonoridades consonantais - oclusivas bilabiais, alveolares ou dentais - enfatiza a vinculação entre a "oḅediência" devida aos "brancosmaior regularidade métrica (a um verso hexassilábico, seguem-se dois heptassilábicos) expressa um estado de estagnação.

Tudo isso poderia parecer algo redundante - pela alusão à escravidão, na estância inicial - ou mesmo contingente - presumindo-se algum conhecimento acerca da autoria empírica, e de tudo o que isso implica, por parte de quem lê; não se pode negligenciar, todavia, a força retórica dessa nomeação, nesse passo específico: ao enunciar a posição opressora da branquitude na estância que de modo mais veemente trata da escravidão, Conceição Evaristo concede a seu poema a força de uma denúncia, não se furtando a identificar os agentes opressores. $\mathrm{O}$ ato de nomeação pode ser compreendido, em outras palavras, como um movimento estratégico, viabilizando uma determinação fundamental para o enfrentamento. Em outro sentido, essa 
explicitação prepara o discurso para um momento de viragem, visto sugerir o reconhecimento dos elementos necessários para a efetivação da resistência.

A última estrofe do primeiro segmento da composição, consoante a divisão proposta para esta análise, traz a terceira figura feminina: a mãe - o que corrobora os indícios, já oferecidos pelas estâncias anteriores, de que o poema descreve um processo que transcorre ao longo de um conjunto de gerações. Embora, a princípio, a mãe não pareça ocupar uma posição diferente daquela ocupada pela avó, e embora também sua voz seja associada a um eco, o segundo verso da estrofe introduz uma ruptura: mesmo que de modo discreto - como denota o advérbio "baixinho", em que ainda se patenteia a situação de domínio -, o que agora a voz ecoa é a revolta; desse modo, a reverberação remete não à mera replicação imposta pela subalternidade, mas a um jogo de ressonâncias coletivamente construído, em direção a um propósito definido: a subversão.

Os versos que se seguem descrevem, com maior minúcia, o cenário de adversidade em que a voz materna se pronuncia. Em decorrência da posição subalterna, resta-lhe percorrer os espaços menos valorizados de um território que não lhe pertence; todavia, mesmo obrigada a ocupar o "fundo das cozinhas", mesmo soando "debaixo das trouxas / roupagens sujas dos brancos", a voz materna logra encontrar uma trilha que lhe permite fugir ao estado de opressão. Note-se que o espaço estranho para o qual a avó fora deslocada à força (isso é: o navio negreiro) não é de todo dessemelhante do lugar em que habita a mãe (isto é: o espaço doméstico), na medida em que ambos constituem territórios alheios, regidos por forças opressoras; entretanto, ao encontrar seu caminho, a mãe inverte o deslocamento imposto à avó: se esta, sequestrada, deixara seu lugar próprio de maneira forçosa, aquela deliberadamente abandona o sítio em que fora confinada, à procura de autonomia.

Cabe, ainda, atentar para o modo como a senda que conduz à emancipação é qualificada: o adjetivo "empoeirado" retoma a ideia de sujidade presente no verso anterior, que remetia à vestes dos brancos; por outro lado, no verso que fecha a estrofe, a referência à favela alude a um território caracterizado por atributos que o distinguem do espaço senhorial. O que essa valoração explicita é a oposição entre um território branco, no qual o corpo negro já estava destinado aos recintos impuros - ao que está no "fundo" ou "debaixo" -, e o território designado aos negros: lá, naquele espaço periférico onde só é possível chegar após percorrer o pó, a libertação se apresenta como um cenário factível. Apenas porque a mãe ousou trilhar esse caminho, a voz lírica terá condições de ecoar uma posição diversa.

$\mathrm{O}$ desvelamento da esperança se traduz, em termos formais, na variedade métrica e rítmica perceptíveis nessa terceira estrofe: por um lado, os versos que a compõem apresentam todas as possibilidades entre o tetrassílabo e o eneassílabo; no que tange ao ritmo, é notável o uso alternado de anapestos e de peões quartos, sugerindo um movimento que cada vez mais se amplifica - até que, no par final de versos, assume a predominância. Também nesses últimos versos, a ênfase em segmentos vocálicos mais baixos e anteriores ("empoeirado", "favela") sugere uma possibilidade de abertura.

A quarta estância de "Vozes-mulheres" constitui o segundo segmento da composição,

Anu. Lit., Florianópolis, v. 24, n. 1, p. 23-32, 2019. ISSNe 2175-7917 
consoante a disposição aqui proposta. A principal diferença perceptível é o fato de que, nessa estrofe, eu lírico ostensivamente manifesta sua própria voz; dessa maneira, trata-se da única estância em que a expressão "A voz de", anaforicamente repetida nas outras estrofes, não ocorre. No desfecho do verso inicial, o advérbio "ainda" assinala o modo como, dialeticamente, a voz inscreve em si as vozes que a antecederam; por conseguinte, aquelas (outras) "vozesmulheres" - da bisavó, da avó e da mãe - não constituem apenas condições de possibilidade para a expressão poética, mas nela se fazem efetivamente presentes. Para além disso, essa presentificação da ancestralidade implica não um mero resgate do passado - enquanto processo que preservaria uma distância temporal -, mas um movimento dialético que as atualiza na voz que, ao pronunciar-se, sintetiza em si todas as presenças e todas as heranças.

Também esta voz se manifesta como um eco - o que, mais uma vez, alude ao produto de uma construção coletiva -, mas sua expressão assume uma forma particular: a de "versos perplexos / com rimas de sangue / e / fome". A materialização da ressonância em registro poético pode aludir à produção de um discurso que, inscrito na ordem do simbólico, do estético e do afetivo (distintamente, por exemplo, do discurso historiográfico ou memorialístico), tem a capacidade de presentificar aquelas vozes revivescendo-as - nesse sentido, ecoando-as não como reflexo tardio de vozes originárias, mas como uma ressonância simultânea: como se todas as "vozes-mulheres", projetando-se ao mesmo tempo, reverberassem umas as outras, potencializando-se mutuamente. No que tange à qualificação dos versos como "perplexos", pode-se interpretá-la à luz da referência ao conteúdo das rimas, tecidas a partir de dolorosas experiências que se dilatam até o presente.

Importa, ainda, ressaltar que a voz-mulher que se manifesta na quarta estrofe já o faz em um lugar próprio - que, considerado-se a referência presente no fim da estância que a antecede, pode ser identificado como a favela; se essa identificação não ocorre de maneira explícita, como no caso das três estrofes anteriores, isso pode ser atribuído ao fato de não haver aqui uma relação de deslocamento ou não-pertencimento semelhante àquelas que determinaram as trajetórias da bisavó, da avó e da mãe. Afirmá-lo não significa esvaziar a favela de seu sentido periférico; trata-se de compreender que, embora assim seja para o senso comum ou para o ordenamento social e político, para o eu lírico não se trata de um lugar estranho, mas sim do território que possibilita a emergência de sua voz.

Os monossílabos presentes no desfecho desta estrofe - que constituem os versos metricamente menos extensos de "Vozes-mulheres" - instituem uma abrupta ruptura, no que tange à dimensão formal da composição, perceptível também no que concerne à sua apresentação gráfica. Seu mais notável efeito diz respeito à estrutura rítmica: em uma estrofe construída a partir de iambos e anapestos, a cisão do último verso força uma interrupção que acaba por produzir uma descontinuidade no momento presente, criando um espaço próprio para a emergência de uma outra voz: a da filha, que protagonizará as duas estrofes finais da composição.

O terceiro e último segmento do poema de Conceição Evaristo, segundo a divisão proposta para esta análise, é constituído pelas duas estrofes que encerram a composição. Uma

Anu. Lit., Florianópolis, v. 24, n. 1, p. 23-32, 2019. ISSNe 2175-7917 
distinção assoma já à primeira vista: o fato de que ambas as estâncias se associam a uma mesma figura feminina; em decorrência disso, a filha ocupa 12 versos da composição - em termos comparativos, observe-se que as outras figuras femininas (a bisavó, a avó, a mãe e aquela que se identifica com o eu lírico) dividem os outros 20 versos do poema. Essa discrepância encontra justificativa, entretanto, quando se considera a função da filha como agente de uma superação explicitada pelo verbo utilizado, num primeiro momento, para qualificar o efeito de sua voz: em contraste com as outras "vozes-mulheres", que "ecoam", a "voz-mulher" da filha "recolhe" (na primeira estrofe do terceiro segmento) para, posteriormente, ecoar (na estância que encerra o poema). Cabe observar atentamente o modo como esses dois movimentos são descritos.

No que concerne ao processo de recolhimento, afirma o texto lírico: “A voz de minha filha / recolhe todas as nossas vozes / recolhe em si / as vozes mudas caladas / engasgadas nas gargantas". A presença do pronome possessivo no verso de abertura não pode ser ignorada, uma vez que inscreve tacitamente a filha no mesmo território em que a voz do eu lírico encontra seu espaço de enunciação; dessa maneira, também ela se encontra em um lugar próprio - que, por sua vez, foi constituído não apenas por sua mãe, mas também pela ação de todas as ancestrais: desde aquela sequestrada para os porões dos navios negreiros, em tempos mais remotos, até as mais recentes mãe e avó, que lograram construir a liberdade no mundo dos "brancos-donos de tudo". O ato de recolhimento, anaforicamente repetido no segundo e no terceiro versos, é descrito com respeito a vozes qualificadas como "mudas", "caladas" e "engasgadas nas gargantas"; em termos retóricos, cabe perceber que essa adjetivação alude a um movimento crescente, que avança desde o emudecimento (a voz da criança que se reduz ao lamento) até o silenciamento (as vozes que se limitam à obediência e aos murmúrios que gestam a revolta) e, finalmente, à dolorosa expressão poética (por meio dos "versos perplexos"). O que assim se evidencia é o modo como essas vozes foram paulatinamente, ao longo de gerações, construindo para si as condições necessárias para a enunciação.

No que tange aos aspectos retóricos e formais, para além da já mencionada repetição anafórica do verbo "recolher" - que ressalta a importância desse ato -, cabe notar também a repetição de "vozes", no segundo e no quarto versos; mais precisamente, no fim daquele e no início deste (à maneira de uma anadiplose que é, todavia, interrompida pela repetição anafórica), aludindo às "vozes-mulheres" que a "voz" citada no verso inicial em si recolhe. Em termos rítmicos, a conjugação de iambos e anapestos ora sustenta um andamento regular mesmo no momento em que há maior variação métrica, entre o segundo verso (eneassilábico) e o terceiro verso (tetrassilábico) -, ora sugere avanços, o que traduz formalmente o processo em que a voz da filha recolhe as outras "vozes-mulheres", subsumindo-as. Cabe, ademais, destacar o contraste entre a assonância presente no início da estrofe (sobretudo no segundo verso, com a repetição enfática das vogais médias posteriores arredondadas: "recolhe", "todas", "nossas", "vozes") e no seu fim (sobretudo no quinto verso, estendendo-se ao desfecho daquele que o antecede, em que ganham destaque as vogais baixas: "caladas", "engasga adas", "gargantas"); neste último ponto, chama a atenção também a aliteração, envolvendo velares oclusivas - um arranjo sonoro que remete às dificuldades implicadas na recolha e síntese das 
outras vozes.

$\mathrm{Na}$ estrofe que encerra "Vozes-mulheres", a superação finalmente tem lugar. A repetição do verso de abertura - "A voz de minha filha", parcialmente retomado como antepenúltimo verso - reitera o protagonismo dessa figura feminina; e a importância de sua ação é explicitada pelo resgate, no segundo verso dessa estrofe, do terceiro verso da estância anterior. Não obstante, quando o eu lírico afirma que o recolhimento operado pela filha envolve "a fala e o ato", torna-se patente que esse processo ultrapassa a dimensão verbal, alcançando também um âmbito performativo - ou, para além disso: existencial. A síntese, portanto, diz respeito aos discursos e às práticas, abarcando heranças que propiciam uma constituição ontológica resultante da soma de movimentos dialéticos: a emergência de uma voz que inaugura, ao fim, um novo modo de existência - e que, em decorrência disso, terá as condições para produzir uma nova ressonância, resultantes da síntese que a "voz-mulher" da filha gesta a partir de si.

A menção de uma tríplice temporalidade ("O ontem - o hoje - o agora") recupera as diversas etapas desse movimento, cabendo perceber que não representam termos isolados, uma vez que todos estão mutuamente implicados: o "ontem" condiciona o "hoje", que determina o "agora"; o "agora" em si subsume tanto o "hoje" quanto o "ontem". O que essa formulação particular da temporalidade faz sobressair é a presença concomitante de todas as "vozesmulheres" - não como figuras cuja ação se realiza em intervalos distintos, mas como agentes que se presentificam em um ato singular, efetivado pelo recolhimento na "voz-mulher" da filha. Há, portanto, uma fundamental diferença qualitativa, visto que essa nova ressonância implica a convergência da coletividade em um lugar próprio (o território que a filha habita graças ao movimento emancipatório do qual participaram sua mãe e sua avó), a partir de uma disposição existencial também nova (mas que não prescinde das existências ancestrais): é disso que provém a "vida-liberdade" - que, enquanto eco, propicia a libertação tanto da filha quanto daquelas que a antecederam.

A rigorosa composição da estrofe final - conjugando tetrassílabos, hexassílabos e eneassílabos - institui uma regularidade métrica diversa, o que traduz o novo ordenamento gerado a partir da "voz-mulher" filha; a presença de peões quartos no desfecho do último par de versos, dilatando ainda mais um movimento já concretizado pela presença de anapestos, expressa a emancipação enfim lograda. Trata-se, enfim, do anúncio definitivo de um novo momento, propiciado unicamente pela ação conjunta das "vozes-mulheres" que, a partir de si mesmas, construíram as trilhas que conduzem à própria autonomia.

\section{Referências}

EVARISTO, Conceição. Poemas da recordação e outros movimentos. 3. ed. Rio de Janeiro: Malê, 2017.

FINNEGAN, Ruth. Oral Literature in Africa. Cambridge: Open Book Publishers, 2012.

IRELE, Fabiola. The African Imagination: literature in Africa and the Black Diaspora. Nova Iorque: Oxford University Press, 2001. 
JAMES, Lawrence B. The influence of black orality on contemporary black poetry and its implications for performance. Southern Speech Communication Journal, Pensacola, n. 45, p. 249-267, 1980.

MBEMBE, Achille. Crítica da razão negra. Lisboa: Antígona, 2014.

MENDES, Ana Claudia Duarte. Eco e memória: "Vozes-mulheres", de Conceição Evaristo. Terra roxa e outras terras - Revista de Estudos Literários, Londrina, v. 17-A, p. 113-122, dez. 2009.

NASCIMENTO, Gizêlda Melo do. Grandes mães, reais senhoras. In: NASCIMENTO, Elisa Larkin (Org.). Guerreiras de natureza: mulher negras, religiosidade e ambiente. São Paulo: Selo Negro, 2008. p. 49-64.

SALGUEIRO, Maria Aparecida Andrade. Escritoras negras contemporâneas: estudo de narrativas: Estados Unidos e Brasil. Rio de Janeiro: Caetés, 2004.

SANTOS, Miriam Cristina. Intelectuais negras: prosa negro-brasileira contemporânea. Rio de Janeiro: Malê, 2018.

SOARES, Isabelle Maria; SANTOS, Maria Fernanda dos; TEIXEIRA, Níncia Cecília Ribas Borges. Vozes-mulheres de Conceição Evaristo: dando voz para a história das mulheres afrobrasileiras. Caderno Espaço Feminino, Uberlândia, v. 31, n. 1, p. 104-118, jan./jun. 2018.

Henrique Marques Samyn (marquessamyn@gmail.com) é professor do Instituto de Letras da Universidade do Estado do Rio de Janeiro, atuando na graduação e na pós-graduação. Suas pesquisas atuais abordam modos de representação de subjetividades e corpos generificados e racializados, desde uma perspectiva interseccional. Coordena o projeto de extensão LetrasPretas, desenvolvido junto a uma equipe de estudantes negras e cotistas da Uerj comprometidas com o estudo e a divulgação da produção literária, cultural e intelectual de mulheres negras.

\section{NOTAS DE AUTORIA}

Como citar esse artigo de acordo com as normas da revista

SAMYN, Henrique Marques. Para (re)ler "Vozes-mulheres": Conceição Evaristo e a dialética da ancestralidade. Anuário de Literatura, Florianópolis, v. 24, n. 1, p. 23-32, 2019.

\section{Contribuição de autoria}

Não se aplica.

\section{Financiamento}

Não se aplica.

Consentimento de uso de imagem

Não se aplica.

Aprovação de comitê de ética em pesquisa

Não se aplica. 


\section{Licença de uso}

Este artigo está licenciado sob a Licença Creative Commons CC-BY. Com essa licença você pode compartilhar, adaptar, criar para qualquer fim, desde que atribua a autoria da obra.

\section{Histórico}

Recebido em: 29/03/2019

Aprovado em: 14/06/2019

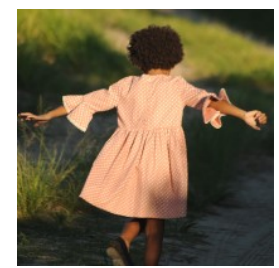

